\title{
LEGISLADORES Y JUECES FRENTE A LA IGUALDAD CONSTITUCIONAL DE LOS SEXOS*
}

\author{
LUIS ALEJANDro SilVA IRARRÁZAVAL** \\ JORGE IGNACIO ARAB MASSUH***
}

\begin{abstract}
RESUMEN: El presente trabajo tiene por objeto el analizar la forma como el Congreso y los Tribunales chilenos han respondido al principio constitucional de la igualdad entre el hombre y la mujer. En el caso del Congreso se sugiere una tipología de la igualdad, en función de los criterios que justificarían las diferenciaciones y las igualaciones entre los sexos. En el caso de los Tribunales de Justicia en Chile, se examinan algunos casos en los que la diferencia de los sexos sería un elemento determinante en la solución del conflicto, y se ofrece una clasificación básica de las actitudes que ha adoptado respecto de la materia.
\end{abstract}

PALABRAS CLAVE: No discriminación - igualdad - igualdad de oportunidades - género - sexo.

\section{LEGISLATORS AND JUDGES OPPOSITE CONSTITUTIONAL GENDER EQUALITY}

ABSTRACT: This paper analyzes the way in which the Chilean Congress and Courts respond to the constitutional principle of equality between man and woman. In the Congress' case, an equality typology is suggested, which is based on the criteria that would justify the differences and equalities between sexes. For the Courts, on the other hand, some cases are examined in which the difference between sexes would be

\footnotetext{
* Agradecemos el apoyo de la Dirección de Investigación de la Universidad de los Andes, y los valiosos comentarios de las profesoras Francisca Jünemann y Anastasia Assimakopulos al borrador de este artículo.

Fecha de recepción: 20 de diciembre de 2012.

Fecha de aceptación: 13 de enero de 2014.

** Doctor en Derecho. Profesor de Derecho Constitucional, Facultad de Derecho de la Universidad de los Andes, Santiago de Chile, Av. Monseñor Álvaro del Portillo 12455, Las Condes. Correo electrónico: 1silva@uandes.cl

*** Abogado. Licenciado en Derecho, Facultad de Derecho de la Pontificia Universidad Católica de Chile. Realizó estudios en Washington D.C, en el Curso de Inclusión Financiera en el Fondo Monetario Internacional. Ayudante de Cátedra de Derecho Constitucional en la PUC (2007-2010). Correo electrónico: jiarab@uc.cl
} 
a decisive factor in resolving the conflict. Finally, a basic classification is provided over the attitudes adopted.

KEY WORDS: Non-discrimination - equality - equal opportunity gender - gender differences.

Sumario: Introducción. 1) Prolegómenos. (1.1) Igualdad, discriminación e injusticia. (1.2) Discriminación por sexo: entre naturaleza y cultura. (1.3) La inevitable concepción antropológica. 2) Garantía constitucional de la no discriminación. (2.1) La igualdad ante la ley: que la ley alcance a los iguales (articulo $19 N^{\circ}$ 2). (2.2) Que la ley se aplique igual a los iguales (artículo $\left.19 \mathrm{~N}^{\circ} 3\right)$. Conclusiones.

\section{INTRODUCCIÓN}

El propósito del presente trabajo es ofrecer una visión panorámica sobre la forma como el Congreso y los Tribunales responden al principio constitucional de igualdad entre el hombre y la mujer. El único mérito de esta investigación sería el haberse enfocado exclusivamente en las exigencias planteadas por las diferencias que nacen de la distinción del sexo, considerando lo relativamente escasa que es la literatura nacional en la materia. Las pretensiones del trabajo son modestas, lo mismo que sus aspiraciones de originalidad: no es un estudio sobre los alcances del principio constitucional de igualdad, sino de algunos casos que ilustran cómo el Congreso y los Tribunales han encauzado la demanda de un trato igualitario entre hombres y mujeres.

La matriz del principio de igualdad de los sexos es el artículo $19 \mathrm{~N}^{\circ} \mathrm{s}$ 2 y 3. De aquí emana la obligación, para el Legislador y para los Jueces, de no discriminar arbitrariamente entre hombres y mujeres en razón del sexo. Para cada uno de estos dos poderes estatales aquella obligación se materializa de un modo particular, adecuado a la naturaleza de su función específica. En términos simples podría decirse que el principio de igualdad debe inspirar al Congreso la dictación/modificación/derogación de leyes, y a los Tribunales la prosecución de los procedimientos judiciales y la dictación de las sentencias.

El trabajo se divide, fundamentalmente, en dos partes. La primera de ellas se centra en el Legislador y en su obligación de respetar la igualdad ante la ley que la Constitución asegura entre hombre y mujer. Esta primera parte de la materia se organizó en torno a cuatro núcleos conceptuales: el símbolo, la igualación, la naturaleza y la cultura. Estos núcleos conceptuales se proponen como puntos de vista eventualmente útiles para identificar las ideas que inspiran la actividad legislativa. 
La segunda parte de este trabajo se centra en la jurisprudencia de los Tribunales, y tiene el propósito de indagar cómo estos han acogido la igualdad entre hombre y mujer. El análisis de la jurisprudencia se divide en dos secciones. Una sección ofrece un panorama de las líneas jurisprudenciales dominantes en materias típicamente conflictivas desde la perspectiva de la igualdad de los sexos. La otra sección, en cambio, consiste en el análisis de dos casos que se salen del patrón jurisprudencial dominante.

Antes del análisis del comportamiento del Legislador y de los Tribunales, hay una parte que podría llamarse de los prolegómenos, porque en ella se resumen algunos conceptos comprendidos en el problema de la igualdad entre el hombre y la mujer. Este resumen cumple con el modesto propósito de esbozar algunas diferencias y matices que conviene tener presentes para una más adecuada comprensión de la materia y una más precisa valoración de la actividad del Legislador y de los Tribunales.

\section{1) Prolegómenos}

Para comprender y valorar más adecuadamente la forma como el Legislador y los Tribunales han satisfecho las exigencias reclamadas por la igualdad entre el hombre y la mujer, parece conveniente desarrollar algunos puntos que están implícitos en el marco de cualquier análisis de la materia. Como se dijo en el párrafo anterior, el desarrollo de estas ideas se justifica solo en función de aquel servicio, razón por la cual resulta -en sí mismo considerado- un ejercicio que podría ser ampliamente profundizado.

\section{1.) IGUALDAD, DISCRIMINACIÓN E INJUSTICIA}

La igualdad/desigualdad es una categoría relativa porque, dependiendo del término de comparación que se elija, de las dos cosas comparadas puede decirse que son iguales o que son desiguales. El hombre y la mujer son iguales en muchos sentidos, pero también son desiguales en muchos otros.

A veces, la relación de igualdad/desigualdad entre las personas tiene un contenido de justicia: algo le es debido a alguien precisamente porque es igual/desigual. La razón de esta exigencia de justicia que nace de la relación igual/desigual entre dos o más personas puede ser natural o positiva. Cualquier acción u omisión que desconozca lo debido a alguien en virtud de su condición de igual/desigual es injusta. Y el Derecho procura evitar la injusticia o corregirla, según sea el caso. En este contexto, la justicia o injusticia de una determinada acción u omisión no puede juzgarse exclusivamente en función de lo que se da o se deja de dar a alguien; es preciso antes responder a la pregunta, ¿le era debido?

Una fórmula típica de la igualdad (que dice poco, pero algo dice) es "tratar igual a los iguales y desigual a los desiguales". En esta formulación 
subyace la distinción entre discriminación justa y discriminación arbitraria. No toda discriminación es injusta o arbitraria, sino solo aquella que no se funda en la razón (positiva o natural). Esta aclaración es útil tenerla siempre presente, porque es común que por inadvertencia se identifique cualquier discriminación con una arbitrariedad que debe ser impedida o corregida. Y no es así ${ }^{1}$.

\section{2.) DISCRIMINACIÓN POR SEXO: ENTRE NATURALEZA Y CULTURA}

Entre el hombre y la mujer existen desigualdades que no se pueden o no se deben corregir, porque responden a diferencias fundadas en la naturaleza. En cambio, existen otras desigualdades que se pueden o se deben corregir, porque se basan en diferencias creadas por la cultura. Entre las desigualdades basadas en la naturaleza hay algunas evidentes, como el hecho del embarazo, que solo puede referirse a la mujer. Lo mismo ocurre con algunas desigualdades basadas en la cultura que son evidentes, como el derecho a votar, proscrito para las mujeres por mucho tiempo.

En general, las discusiones sobre las exigencias del principio de igualdad entre el hombre y la mujer se conciben en una lógica dialéctica entre la naturaleza y la cultura ${ }^{2}$. Simplificando las cosas, se puede caracterizar el debate como un forcejeo para decidir dónde se establece en cada caso lo que es natural y lo que es cultural. Y se asume que si es cultural, puede (o debe) cambiarse. Para los casos extremos, este marco conceptual es útil: es evidente la indisponibilidad de ciertas desigualdades, porque están basadas en la naturaleza distinta del hombre y la mujer; así como es evidente la disponibilidad de ciertas desigualdades, porque están basadas en una determinada y contingente concepción cultural. Pero la enorme mayoría de los casos no puede resolverse con este criterio.

Existe un número inmenso de situaciones en que las diferencias entre el hombre y la mujer no pueden fácilmente caracterizarse como naturales o culturales. Y sin embargo, la correcta comprensión del carácter de esa desigualdad es determinante para decidir el alcance de la intervención

1 La bibliografía sobre la igualdad jurídica es demasiado amplia como para pretender dar cuenta de ella en una nota. Nos contentamos con sugerir Boвbio, Norberto (1993): Igualdad y libertad. Barcelona: Editorial Paidós, 154 pp; y Pérez Luño, Antonio Enrique (2007): "Dimensiones de la igualdad", Cuadernos "Bartolomé de las Casas". 2a edición. Madrid: Editorial Dykinson. Vol. 34, 135 pp. Más específicamente en la materia: Ollero, Andrés (1999): Discriminación por razón de sexo: valores, principios y normas en la jurisprudencia constitucional española. Prólogo de Miguel Rodríguez-Piñero Bravo-Ferrer. Madrid: Editorial Centro de Estudios Políticos y Constitucionales, 183 pp.

2 Novales, Aránzazu (2004): Derecho antidiscriminatorio y género: las premisas invisibles, Santiago de Chile: Fondo de Desarrollo de las Naciones Unidas para la Mujer, en los capítulos I y II de la Primera Parte (pp. 47-I72) muestra que, al problema de la discriminación por razón de sexo, subyace la tensión de las diferencias culturales y las naturales. 
legislativa o judicial, según sea el caso. En estos casos, admitir la tensión dialéctica entre naturaleza y cultura es un error, porque lo natural y lo cultural no son cualidades independientes, sino interdependientes. La naturaleza "no está antes de la cultura, sino más bien se desvela en los desarrollos culturales que son los que posibilitan al hombre actuar como tal"3.

Es importante tener presente la indisoluble relación que hay entre naturaleza y cultura cuando se trata de juzgar las desigualdades entre el hombre y la mujer, porque los prejuicios ideológicos tergiversan la realidad, presentándola en antinomios (naturaleza/cultura es uno de ellos) que empobrecen su comprensión. Y de aquí se siguen, con frecuencia, decisiones que perjudican a la mujer en primer lugar, pero a la sociedad entera luego. Ahora bien, esta forma de comprender la realidad (la naturaleza que se expresa a través de la cultura) entraña como condición y complemento, una concepción filosófica de la persona humana.

\section{3.) LA INEVITABLE CONCEPCIÓN ANTROPOLÓGICA}

En la determinación del sentido y alcance del principio constitucional de no discriminación desde una perspectiva de sexo, no puede prescindirse de una concepción filosófica de la persona humana. En primer lugar, porque la visión antropológica que se tenga determinará una buena parte de los derechos y deberes que se reconozcan a la mujer por ser mujer y al hombre por ser hombre. En segundo lugar, porque la filosofía del hombre condiciona la filosofía política y, en consecuencia, el rol del Estado, la naturaleza de la ley, etc.

En los debates acerca de las implicancias del principio de igualdad entre el hombre y la mujer no existen las posturas "neutras" u "objetivas" ". Todas son siempre subjetivas; valóricamente cargadas. Otra cuestión es que, por razones estratégicas, esto quiera disimularse, negándolo. En el fondo de cualquier posición sobre el significado concreto del principio de no discriminación a la mujer, existe una visión de la persona humana que inspira la defensa o promoción de unas determinadas exigencias en nombre de la igualdad.

El reconocimiento de la inevitable concepción antropológica que subyace a la cuestión de la igualdad hombre-mujer, es conveniente por algunas razones. Una de ellas es que sirve como patrón de referencia para la

3 Peña, Jorge (2000): "Las diversas acepciones de naturaleza en su relación con la cultura", Anuario de filosofía jurídica y social, $\mathrm{N}^{\circ} 18$, p. 56. En el mismo sentido, Arregui, Jorge y Rodríguez, Carlos (1995): Inventar la sexualidad: sexo, naturaleza y cultura. Madrid: Ediciones Rialp, S.A., pp 87-98.

4 Sandel repite varias veces esta aclaración, a propósito de distintas discusiones jurídicas de alto contenido moral. SANDEL, Michael (2010): Justicia: ¿Hacemos lo que debemos? Barcelona: Editorial Debate, 352 pp. 
promoción de políticas públicas (leyes) consistentes entre sí. Otra, es que transparenta el debate, eliminando la falaz distinción entre el grupo de "los abiertos" (que se presentarían como neutrales y objetivos) y "los cerrados" (que reconocerían su adhesión a ciertas convicciones antropológicas).

\section{2) GARANTÍA CONSTITUCIONAL DE LA NO DISCRIMINACIÓN}

La igualdad es expresión de la justicia, en la medida que la justicia significa una cierta proporción. Con otras palabras, puede decirse que la igualdad es una exigencia de la justicia, en la medida que consiste en "dar a cada uno lo suyo". En este sentido, la igualdad siempre ha sido un factor determinante del Derecho (porque la justicia lo es). Sin embargo, en la Revolución Francesa la igualdad adquirió una especificidad propia, cristalizando como un nuevo derecho5 ${ }^{5}$. Desde entonces, la igualdad ha catalizado en buena medida el discurso del progreso humano ${ }^{6}$.

La igualdad en Chile tiene reconocimiento constitucional temprano en nuestra historia ${ }^{7}$. Actualmente, es un valor que empapa toda la Constitución, aflorando en una serie de preceptos. Además, se manifiesta en muchas normas jurídicas de las más variadas fuentes y jerarquías, que caracterizan sus exigencias en determinados supuestos específicos a lo largo y ancho del ordenamiento chileno.

La garantía constitucional de la igualdad o no discriminación está consagrada en el artículo $19 \mathrm{~N}^{\circ}$ s 2 y 3 . En el primer número se asegura a todas las personas la igualdad ante la ley y en el segundo número la igualdad en la protección de los derechos. Podría decirse que en el primer caso la garantía está dirigida al Legislador y en el segundo caso al Juez. Estos dos numerales no son las únicas disposiciones constitucionales que reconocen expresamente la igualdad, pero sí constituyen su expresión más amplia o general.

La igualdad ante la ley y la igual protección de los derechos, tal y como están formuladas en los $\mathrm{N}^{\circ}$ s 2 y 3 del artículo 19, constituyen la matriz de la exigencia constitucional de la igualdad en Chile. Todas las demás expresiones normativas de esta exigencia constitucional -cualquiera sea su naturaleza o su origen- pueden ser remitidas a una de estas dos garantías. Por esta razón es que se examinarán a continuación.

\footnotetext{
5 Una buena síntesis en Rosanvallon, Pierre (2012): La Sociedad de los Iguales. Barcelona: Editorial RBA Libros, 428 pp.

PÉREZ-Luño (2007), pp. 5 I-74.

Fernández, Miguel Ângel (2001): Principio constitucional de igualdad ante la ley. Santiago: Editorial ConoSur, pp. 117-118.
} 


\section{1.) LA IGUALDAD ANTE LA LEY: QUE LA LEY ALCANCE A LOS IGUALES (ARTÍCULO $19 \mathrm{~N}^{\circ}$ 2)}

La igualdad ante la ley, según una fórmula típica, significa que la ley debe tratar igual a los iguales y desigual a los desiguales. En palabras del Tribunal Constitucional: "la igualdad ante la ley consiste en que las normas juridicas deben ser iguales para todas las personas que se encuentren en las mismas circunstancias $y$, consecuencialmente, diversas para aquellas que se encuentren en situaciones diferentes. No se trata, por consiguiente, de una igualdad absoluta sino que ha de aplicarse la ley en cada caso conforme a las diferencias constitutivas del mismo. La igualdad supone, por lo tanto, la distinción razonable entre quienes no se encuentren en la misma condición" ". Quiénes son los iguales y quiénes los desiguales toca definirlo al Legislador. Por esto, la exigencia que la igualdad ante la ley plantea a los legisladores es que las leyes que dictan no excluyan a nadie que debía estar incluido, ni incluyan a nadie que debía estar excluido. Una ley que no satisface esta exigencia es contraria a la garantía del artículo $19 \mathrm{~N}^{\circ} 2$. La definición legislativa sobre quiénes son los iguales y quiénes los desiguales no puede ser caprichosa, sino que debe justificarse racionalmente. Han de haber razones que expliquen el porqué de una definición. Cuando las razones son aceptables, la definición legal de los iguales y de los desiguales no es inconstitucional. En cambio, cuando no hay razones suficientes o las razones no son aceptables, la definición legal (es decir, la diferencia entre los iguales y los desiguales) es arbitraria o inconstitucional ${ }^{9}$.

Toda ley implica una discriminación, en la medida que define un grupo de personas a las que se aplica y otro a las que no. Las discriminaciones legales que carecen de fundamento racional suficiente son arbitrarias; las leyes que así discriminan son inconstitucionales. Ahora bien, la suficiencia de las razones para justificar una decisión legislativa desde el punto de vista de la igualdad es una cuestión ardua que, en definitiva, dependerá de la prudencia política.

En virtud de la igualdad, el Legislador crea, reforma y elimina leyes ${ }^{10}$. Pero al contrario de lo que pudiera parecer, esta actividad legislativa no es uniforme, sino rica en matices. Las formas en que el Legislador puede satisfacer las exigencias de la igualdad o no discriminación son mu-

\footnotetext{
8 Tribunal Constitucional. 29 de julio de 2009. Rol No 1254. Publicación en el Diario Oficial, 1 de agosto de 2009, 30 pp. (Considerando 46. La cita interna corresponde a las sentencias roles $\mathrm{No}^{\circ}$. 28, 53 y 219).

9 El Tribunal Constitucional tiene una jurisprudencia relativamente bien asentada en este punto. Una síntesis en Navarro, Enrique (2012): "Igualdad ante la ley y jurisprudencia del Tribunal Constitucional" en Actualidad Juridica, Vol. 13, № 26, pp. 63-96.

10 Aquí se incluye la reforma de la Constitución y la ratificación de tratados internacionales.
} 
chas, porque muchas y de muy distinta naturaleza pueden ser las razones esgrimidas en nombre de la igualdad.

El análisis de las formas en que el Legislador ha respondido a los requerimientos del principio constitucionalidad de la igualdad de los sexos lo hemos ordenado en torno a cuatro núcleos conceptuales: el símbolo, la igualación, la naturaleza y la cultura. Como se ha dicho más arriba, el propósito de estos núcleos conceptuales es ofrecer distintas perspectivas para una mejor comprensión del trabajo del Legislador en la materia.

\subsection{1.) Igualdad simbólica}

La ley cumple una función simbólica: a través de su texto transmite unos contenidos que tienen efecto en sus destinatarios, aunque sea irrelevante como regla para decidir un conflicto. El Legislador a veces se sirve de la ley para simbolizar algo. En el contexto de este trabajo, diremos que el Legislador se sirve de la ley para simbolizar la igualdad que existe entre el hombre y la mujer.

Si bien de cualquier ley puede predicarse un significado simbólico, en este apartado queremos fijar la atención en aquellos casos en que la única función que cumplen es de carácter simbólico. Esto significa que la creación/reforma/derogación de una ley tiene como única finalidad simbolizar el principio de igualdad o no discriminación entre el hombre y la mujer. Dos casos para ilustrar este punto.

- La reforma del artículo 1 inciso $1^{\circ}$ de la Constitución

La ley $\mathrm{N}^{\circ} 19.611$ (D.O. 16 de junio de 1999) que reformó la Constitución, tuvo una finalidad exclusivamente simbólica. Dicha reforma constitucional sustituyó la expresión "Los hombres" del artículo 1 por "Las personas", y agregó al final del párrafo primero del artículo 19 N² la oración "Hombres y mujeres son iguales ante la ley". Como queda de manifiesto en el Mensaje del proyecto de esta ley de reforma de la Constitución, la iniciativa reconoce que su objeto es "explicitar la igualdad jurídica entre hombres y mujeres" 11 .

Los autores del proyecto de reforma del artículo 1 y $19 \mathrm{~N}^{\circ} 2$ de la Constitución admiten que la expresión "Los hombres" del artículo 1 comprende tanto a las mujeres como a los hombres ${ }^{12}$. No obstante, el término expresaría un "prejuicio sexista", porque "refuerza estereotipos y prácticas discriminatorias, destacando el protagonismo de los hombres y ocultando el de las mujeres"13. El lenguaje utilizado por la Constitución no es inocuo

Historia L. 19.611 , p. 4

No podía ser de otro modo, al tenor del artículo 25 del Código Civil.

Historia L. 19.611, p. 5. 
para los promotores de la iniciativa, sino que "influye en nuestra percepción de la realidad"14. Por esto es que la reforma en cuestión, aunque sea simbólica, no es inútil.

Esta reforma de la Constitución no obedeció a ninguna necesidad práctica, porque nunca antes de ella hubo alguna discriminación arbitraria entre hombre y mujer que se sirviera de la expresión "Los hombres" del artículo 1, o de la ausencia de una aclaración como la ańadida al artículo $19 \mathrm{~N}^{\circ} 2$. Y tampoco ninguna consecuencia práctica se ha seguido después de que la reforma entró en vigencia. "Se trató de una reforma que tiene sobre todo una potencialidad simbólica y de énfasis politico, pero de dudosas repercusiones prácticas en el plano dogmático-juridico"15.

- La creación del delito de femicidio (artículo 390 inciso 2o del Código Penal)

La ley $\mathrm{N}^{\circ} 20.480$ creó un nuevo tipo penal en Chile: el femicidio. Este delito quedó consagrado en el inciso 2o del artículo 390 del Código Penal: "El que, conociendo las relaciones que los ligan, mate a su padre, madre o hijo, a cualquier otro de sus ascendientes o descendientes o a quien es o ha sido su cónyuge o su conviviente, será castigado, como parricida, con la pena de presidio mayor en su grado máximo a presidio perpetuo calificado. Si la víctima del delito descrito en el inciso precedente es o ha sido la cónyuge o la conviviente de su autor, el delito tendrá el nombre de femicidio".

A nivel doctrinal, el femicidio consiste en "el asesinato de mujeres por razones asociadas a su género. Se trata de muertes intencionales y generalmente violentas de mujeres por el hecho de ser mujeres"16. La reforma al Código Penal en este punto estuvo explícitamente inspirada como una iniciativa para igualar a la mujer con el hombre. En principio, esta igualación se expresaría en un delito con penas más severas que el asesinato de hombres (idea que no prosperó finalmente); pero además, y siempre, la igualación se daba simbólicamente al consagrar el nombre "femicidio"17.

El carácter simbólico de la creación del femicidio podría deducirse del mismo texto del artículo 390 del Código Penal, porque el inciso $2^{\circ}$ no agrega nada al inciso $1^{\circ}$, excepto el nombre del delito cuando la persona

14 Historia L. 19.611 , p. 5.

15 Corral, Hernán (2007): Derecho civil y persona humana. Cuestiones debatidas. Santiago: LexisNexis, p. 46.

16 Historia L. 20.480, p. 49. Un matiz que debilita esta definición, es el supuesto en que la muerte es ocasionada por una mujer, ya que nada impide el femicidio en supuestos de relaciones lésbicas: Santibañez, María Elena y Vargas, Tatiana (2011): "Reflexiones en torno a las modificaciones para sancionar el femicidio y otras reformas relacionadas (ley $\mathrm{N}^{\circ}$ 20.480)", en Revista Chilena de Derecho, Vol. 38 N $^{\circ}$ 1, p. 205.

17 En la moción que dio origen a esta ley, se reconoce que la creación del femicidio constituirá una señal "mediática y cultural", en orden a reprobar el asesinato de mujeres (Historia L. 20.480, p. 5). 
asesinada era la cónyuge o conviviente del autor. Se deduce el carácter simbólico porque, si el inciso $2^{\circ}$ no agrega nada, ¿para qué existe? Pero la historia de la ley $\mathrm{N}^{\circ} 20.480$ deja constancia expresa de este carácter simbólico del femicidio. En palabras de Raúl Carnevali: "Considerando que ya existen los tipos penales que recogen los supuestos que se comprenderian en el femicidio, parece apreciarse que esta reforma apunta, de manera especial, a resaltar el impacto social que hechos de esta naturaleza generan. Apreciado asi, aquello no puede valorarse negativamente, pues, es innegable la carga simbólica de ciertas palabras -nomen iuris- y las repercusiones que aquello tiene para el Derecho Penal"18.

\subsection{2.) Igualdad e igualación}

Igualación es la acción o efecto de igualar, e igualar en este contexto es sinónimo de empatar, de uniformar, que es algo distinto de la igualdad jurídica. En los casos que se comprenden en esta sección, la igualdad de los sexos es el argumento para igualar a las mujeres con los hombres, resultado que se puede comprender en el género de las llamadas "discriminaciones positivas" 19 . En este tipo de casos, el Legislador pretende satisfacer las exigencias de la igualdad constitucional de los sexos dando exactamente lo mismo a uno y a otro. La igualación opera aquí como criterio rector de las decisiones legislativas. Son dos los casos con los que se quiere ilustrar este modo de cumplir con la garantía del artículo $19 \mathrm{~N}^{\circ} 2$ de la Constitución.

- El proyecto de ley de cuotas de participación política ${ }^{20}$

Actualmente se tramita un proyecto de ley para "promover el derecho de las mujeres a participar en la vida pública nacional” (Boletín 3206-

Historia L. 20.480, p. 69. Otras opiniones que constan en la Historia: "Estos esfuerzos de dar una mayor connotación en contra de los crímenes de las mujeres [creando el femicidio] se inserta en la idea del poder simbólico del derecho para disuadir estas conductas" (Lidia Casas, p. 76); "La violencia contra las mujeres es un fenómeno de profundo arraigo cultural (...) El proceso de identificarla y nombrarla, de poner en el lenguaje signos que den cuenta de ella (...) ha sido lento y no exento de resistencias. Sin embargo, hoy día, cuando hablamos de femicidio la mayoría del país identifica el problema y sabe de qué estamos hablando" (Soledad Rojas, p. 74); la opinión del profesor Jaime Vera, en p. 100; el Informe de la Comisión de Familia de la Cámara de Diputados, p. 131; la intervención de la impulsora del proyecto, María Antonieta Saa, en la discusión general en la Cámara de Diputados, p. 471.

19 La bibliografía sobre discriminación positiva es amplísima. En el contexto de las desigualdades por razón del sexo, Gímenez Gluck, David (1999): Una manifestación polémica del principio de igualdad: acciones positivas moderadas y medidas de discriminación inversa. Valencia: Editorial Lo Blanch, pp. 58-75. Una ponderada aproximación a la materia: BARRÈRE, María Ángeles (1997): Discriminación, derecho antidiscriminatorio y acción positiva en favor de las mujeres. Madrid: Civitas, 123 pp.

20 Un reconocimiento explícito a la función estratégica de las leyes de cuotas, en Ríos et al. (2008): "El efecto de las leyes de cuota en la representación de las mujeres en América Latina", en Ríos, Marcela (edit), Mujer y Politica. El impacto de las cuotas de género en América Latina (FLACSO-CHILE e IDEA Internacional), p. 221. 
18) 21 . Fundamentalmente, la iniciativa consiste en asegurar que, tanto en la composición de los órganos colegiados de los partidos políticos como en las listas de candidatos, ningún sexo supere el $60 \%$ del total de miembros o candidatos.

El propósito de esta reforma legal es corregir la preponderancia de los hombres en la participación política activa, asegurando a la mujer unos espacios exclusivos para ellas. Entre los considerandos de la iniciativa se lee, por ejemplo, que pese a los esfuerzos, "no se ha logrado una participación [politica] igualitaria entre los sexos, registrándose una abierta desproporción en desmedro de la mujer en la distribución de los cargos directivos de los partidos politicos y en las autoridades edilicias y parlamentarias" (considerando tercero). También, que Chile "no ha promovido hasta ahora politicas de acción positiva orientadas a corregir desequilibrios en la participación de mujeres y hombres en la vida social y politica" (considerando séptimo) 22.

Es evidente la diferencia que existe entre la participación de hombres y mujeres en la dirección de partidos políticos, gobiernos municipales y escańos parlamentarios. Lo que no es evidente, es que la menor presencia de la mujer se explique por una discriminación en razón de su sexo. De hecho, al lado de las mujeres, son muchos los grupos que están infrarrepresentados en la participación política: minorías étnicas, jóvenes entre 25-30 años, trabajadores artesanales, etc. La decisión de legislar en favor de la participación política femenina igualando sus cuotas con las de los hombres parece ser mucho más una decisión política que de satisfacción de un deber de justicia, sobre todo porque no existe ninguna disposición legal que restrinja la participación de las mujeres ${ }^{23}$.

- $\quad$ Ley de igualdad de remuneraciones ${ }^{24}$

La existencia de estudios que muestran en general una desigualdad en las remuneraciones entre hombres y mujeres, parece probar que la

21 Boletín 3206-18, Modifica diversos cuerpos legales con el objeto de promover el derecho de las mujeres a participar en la vida pública nacional, en http://www.camara.cl/pley/pley_detalle.aspx?prmID $=3456$

22 Un diagnóstico del caso chileno, de idéntica inspiración a la de esta ley, en Programa De las Naciones Unidas para el Desarrollo (2010): Desarrollo humano en Chile: género: los desafios de la igualdad. Santiago: PNUD, pp. 265-284.

23 Rodríguez, Marcela (1999), en Género y Derecho, Alda Facio y Lorena Fries (edits.) Santiago, LOM, pp. 245-287, defiende que sí es una exigencia de justicia. Un esfuerzo de conciliación entre las cuotas para mujeres y la teoría de los principios de Robert Alexy, en Elósegui, María (2003): Las acciones positivas para la igualdad de oportunidades laborales entre mujeres y hombres: un análisis de la legislación alemana y la Directiva 76/207/CEE desde la teoría de la argumentación de Robert Alexy. Madrid: Editorial Centro de Estudios Políticos y Constitucionales, pp. 53-117.

24 Sobre la constitucionalidad de la discriminación positiva en esta materia, Gamonal, Sergio (2001): "La lucha contra la discriminación femenina: las acciones positivas y su constitucionalidad”, en Revista Laboral Chilena, $\mathrm{N}^{\circ}$ 98, pp. 69-79. Más general, CAAmaño, Eduardo (2005): El derecho a la no discriminación en el empleo. Santiago de Chile: LexisNexis, pp. 93-102. 
causa es la arbitraria discriminación en contra de las mujeres en el mundo laboral (tradicionalmente masculino) ${ }^{25}$. Que los hombres ganen más y las mujeres menos en trabajos que son equiparables, sería expresión de una cultura de cuño machista. Así se entendió durante la tramitación de la ley 20.348 "que modifica el Código del Trabajo resguardando el derecho a la igualdad en las remuneraciones": "la brecha salarial es un fenómeno de creciente ocurrencia que debe ser erradicado de nuestras prácticas laborales, dado que significa perpetuar una discriminación sin ningún fundamento, que atenta claramente contra el principio de igualdad que debe regir entre hombres y mujeres" 26 .

En principio, la ley $\mathrm{N}^{\circ} 20.348$ vino a remediar la discriminación que afectaba a las mujeres, al definir que el empleador deberá cumplir con el principio de igualdad de remuneraciones entre hombre y mujer ${ }^{27}$. La desigualdad de ingresos entre los hombres y las mujeres como resultado de una injusticia, fue una premisa durante la tramitación de la ley. Así lo prueban las palabras de la entonces Presidenta de la República: "estamos como país cumpliendo con un imperativo ético de demostrar, en la práctica, que los hombres y las mujeres son de verdad iguales ante la ley. Y el 2 de junio será desde ahora un hito en la lucha contra la discriminación que sufren muchas mujeres. Al promulgar la ley que asegura la igualdad de remuneraciones de hombres y mujeres, la verdad que lo que estamos haciendo es nada menos que un acto de justicia, porque era una tarea pendiente"28. Gracias a esta ley, "la igualdad en materia de remuneraciones es ahora un derecho fundamental de todas las mujeres" 29 .

El Legislador identifica una diferencia de trato entre hombres y mujeres, juzga que esa diferencia es injusta y, por lo tanto, que debe ser corregida. La forma en que el Legislador corrige la desigualdad es igualando a las partes. Se asume que la manera de satisfacer la exigencia que plantea el principio de igualdad en el supuesto de las remuneraciones por el tra-

25 Programa de las Naciones Unidas para el Desarrollo (2010) pp. 134-145; HenRÍQuez, Helia y Riquelme, Verónica (2010): “El derecho a ganar lo mismo: ley 20.348 : igualdad de remuneraciones entre hombres y mujeres”, Temas Laborales, № 27, pp. 9-12.

26 Historia L. 20.348, p. 55.

27 Henríquez y Riquelme (2010), pp. 20-22.

28 Presidenta Michelle Bachelet, en el discurso pronunciado el 2 de junio de 2009, con ocasión de la promulgación de la ley (p. 248).

29 Presidenta Michelle Bachelet, en el discurso pronunciado el 2 de junio de 2009, con ocasión de la promulgación de la ley (p. 249). Sobre la concepción de la igualdad de remuneración como un derecho fundamental, en la jurisprudencia europea, GonzÁlez del TÁNAGo, Lourdes et al. (1993); Igualdad de trato entre mujeres y hombres en la jurisprudencia europea. Madrid: Consejería de Presidencia, Dirección de la Mujer, Dirección General de Cooperación con el Estado y Asuntos Europeos, pp. 29-243; y en la jurisprudencia española: AzKÁRATE, Ana Carmen (1997): Mujer y discriminación: del tribunal de justicia de las comunidades al tribunal constitucional. Bilbao: Instituto Vasco de Administración Pública, pp. 89-130. 
bajo profesional es establecer que todos los que se hallan en circunstancias equivalentes deben recibir un sueldo equivalente.

Un problema que plantea el caso de la igualación de las remuneraciones, como lo hace el de las cuotas de participación política, es que no parece suficientemente demostrado que la desigualdad de hecho existente entre los ingresos laborales de hombres y mujeres sea consecuencia de una discriminación arbitraria en contra de las mujeres. Del hecho de ser más bajos en general los ingresos de las mujeres no se infiere necesariamente en su origen una discriminación injusta basada en el sexo. Aunque no es una demostración concluyente de lo anterior, sirve para ilustrar lo que estamos diciendo considerar la cantidad de otras comparaciones que dan el mismo resultado que esta entre hombres y mujeres. Por ejemplo, las diferencias de sueldos que existen entre profesionales egresados de distintas universidades; o entre trabajadores que viven en distintas comunas; o entre empleados que tienen distinta presencia personal, etc. Lo que tratamos de decir es que la comparación entre hombres y mujeres en función del ingreso es una de muchas comparaciones que pueden hacerse, con igual resultado: una desigualdad genérica.

A la luz de estos dos casos de igualación, puede decirse que la diferencia entre los sexos es un criterio que no tiene la potencia explicativa que se le atribuye. La diferencia fáctica que hay entre hombres y mujeres en el ámbito de la participación política y de las remuneraciones no basta para justificar la existencia de una discriminación arbitraria. Parafraseando a Benjamín Cardozo, cabe aquí recordar que los hechos por sí solos no explican nada; antes bien son los hechos los que requieren una explicación ${ }^{30}$.

Quizá sea en este conjunto de casos, en que el Legislador cree corregir ciertas diferencias de hecho existentes entre los sexos, el que más fácilmente permite traslucir las premisas extrajurídicas en que se fundamentan las correspondientes medidas. Precisamente porque es más difícil justificar la igualación de los sexos como medida correctiva de una discriminación arbitraria basada en el sexo, es que las concepciones que se tengan de los que es cultural/natural, o de lo que es la persona humana, tienen una preponderancia mayor.

\subsection{3.) Igualdad natural}

En esta categoría se comprenden las exigencias de justicia que el Legislador entiende se fundamentan en la natural desigualdad entre el hombre y la mujer. Lo característico de las desigualdades que se fundan en la natural diferencia entre el hombre y la mujer es su carácter indisponible:

30 Cardozo, Benjamín N. (1922): The Nature of the Judicial Process. Oxford University Press, $180 \mathrm{pp}$. 
no pueden modificarse por la ley. El ámbito de estas desigualdades "naturales" que exigen un reconocimiento legal es más o menos amplio, según quien lo defina. En este punto, las diferentes visiones de lo que es natural y de lo que es cultural son determinantes. En cualquier caso, todavía existen diferencias legales entre el hombre y la mujer que pueden entenderse fundadas en la naturaleza diferente de los sexos y, precisamente por eso, están reconocidas en la ley. Algunos ejemplos que podrían comprenderse en esta categoría son:

El delito de violación. En este delito solo el varón puede ser sujeto activo porque la mujer, por razones fisiológicas, no puede acceder carnalmente (elemento esencial del tipo). Luego, la mujer está excluida del supuesto de hecho del delito de violación, precisamente por razón de su sexo. La diferencia que la ley establece entre el hombre y la mujer al definir que solo el varón puede ser castigado por el delito de violación sería, en este caso, la forma como el Legislador reconoce y satisface una diferencia entre los sexos que se fundamenta en la naturaleza misma.

El delito de aborto. No puede haber aborto si no hay una mujer embarazada (elemento esencial del tipo). La mujer integra esencialmente el tipo penal del aborto, precisamente porque es mujer ${ }^{31}$. El hombre es naturalmente incapaz de quedar embarazado, por lo que resulta imposible que pueda padecer un aborto. Luego, existe una diferencia entre el hombre y la mujer que se expresa en la definición del delito de aborto. Esta diferencia es el modo como el Legislador reconoce y satisface una distinción entre los sexos que se origina en la naturaleza de las cosas

El período postnatal. Las mujeres, y no los hombres, gozan de un descanso postnatal de 12 semanas. La razón que fundamenta esta diferencia legal entre los sexos es que solo las mujeres pueden dar a luz. Esta circunstancia, que de hecho diferencia al hombre de la mujer, no es cultural sino natural. El Legislador reconoce esta diferencia natural y, en virtud del principio de igualdad constitucional entre los sexos, la corrige, compensa o satisface, estableciendo por ley una diferencia entre el hombre y la mujer ${ }^{32}$.

31 Por supuesto, esta circunstancia no excluye la responsabilidad penal de los demás que intervengan en el aborto, con independencia de su sexo.

32 Podrían sumarse a estos ejemplos todos los que tengan que ver con el embarazo (por ejemplo, el artículo 10 de la ley $\mathrm{N}^{\circ} 18.216$, que deja al juez la posibilidad de suspender el cumplimiento de la pena de reclusión nocturna a la mujer que se encuentra embarazada. Evidentemente, esta es una causal imposible de alegar a favor de un hombre, porque un hombre no puede estar embarazado. Lo mismo podría decirse respecto del artículo 201 del Código del Trabajo), el parto (por ejemplo, el artículo 183 del Código Civil, cuando dispone que la maternidad queda determinada por el parto) y la lactancia (por ejemplo, el artículo 206 del Código del Trabajo, incorporado por la ley $\mathrm{N}^{\circ} 20.166$ (2007) que "extiende el derecho de las madres trabajadoras a amamantar a sus hijos aun cuando no exista sala cuna"), porque son situaciones que solo pueden predicarse de la mujer por razón de su sexo. 
Como se adelantó, el ámbito de las diferencias basadas en la naturaleza es incierto, en la medida en que las concepciones sobre lo que es cultural y lo que es natural pueden ser distintas. Un ejemplo que ilustra el punto es el artículo 26 del Código Civil, que define la edad del impúber distinguiendo entre el hombre y la mujer. El Código Civil establece una evidente diferencia entre los sexos, porque establece que la mujer es adulta antes que el hombre. La cuestión es por qué. Dicha diferencia, que puede tener muchas y serias consecuencias prácticas, ¿je fundamenta en una diferencia natural, como la que justifica las otras diferenciaciones que se han visto en este apartado, o en una diferencia cultural?

\subsection{4.) Igualdad cultural}

Existen exigencias del principio de igualdad entre el hombre y la mujer que responden a patrones culturales. Estas exigencias se caracterizan porque, a diferencia de las exigencias naturales, cambian si lo hacen las condiciones culturales. Sería un error calificar como injustas per se las diferencias legales que se basan en razones culturales, porque "la cultura es la naturaleza humanizada'33. Asimismo, sería un error pensar que solo son desigualdades las que la ley refleja por razones culturales; hay también "igualdades" entre el hombre y la mujer que responden a razones culturales.

Muchas de las diferencias legales existentes entre el hombre y la mujer se atribuyen a la cultura marcadamente machista que ha caracterizado la configuración del derecho occidental ${ }^{34}$. De aquí se seguiría la arbitrariedad del criterio de diferenciación, que tornaría la ley injusta. Lo mismo que se dijo con ocasión de la igualdad natural vale para la igualdad cultural: su ámbito es incierto, porque las concepciones sobre lo que es exigido por la naturaleza y lo que es exigido por la cultura varían.

Existen ejemplos donde parece claro que el motivo del desigual trato que la ley dispensa al hombre y a la mujer se basa en criterios culturales. Esta claridad es mayor en la medida en que el contexto cultural en que nacieron desaparece. En estos casos, en que existe consenso sobre la superación de la cultura en que se incardinaba esa desigualdad legal, lo que se impone es eliminarla. Algunos ejemplos que podrían señalarse para ilustrar este punto: el reconocimiento del sufragio femenino, la aceptación de que exista violación entre los cónyuges, la eliminación del adulterio de la madre como inhabilidad automática para el cuidado personal de los hijos, la despenalización del adulterio de la mujer.

33 Spaemann, Robert (1991): Felicidad y benevolencia. Madrid: RIALP. p. 245.

34 Entre nosotros, la tesis doctoral de la profesora Yanira Zúñiga, es un buen ejemplo de esta lectura. ZúñIga, Yanira (2003): El derecho al desarrollo desde la perspectiva de género, disponible en http://hdl.handle.net/10016/565 
Otros muchos ejemplos, en cambio, ilustran lo difícil que resulta identificar si la desigualdad legal entre el hombre y la mujer responde a razones naturales o culturales. Un buen ejemplo de esta ambigüedad es el caso de la tuición supletoria de los hijos. El Código Civil, en su artículo 225, dispone que si los padres viven separados, corresponde a la madre la tuición de los hijos. ¿Por qué? Porque se supone que la madre es más idónea que el padre para criar a los hijos menores. Pero esta supuesta idoneidad de la madre, ¿es reflejo de una condición natural o cultural?

Lo característico de este conjunto de casos es la función de la cultura como criterio rector para definir la posición del Legislador frente a una eventual discriminación basada en el sexo. El Legislador corrige las discriminaciones arbitrarias cuando el contexto cultural que las podía justificar se debilita o desaparece. Normalmente, es preciso justificar el carácter cultural de la discriminación que se pretende corregir. Como se ha observado anteriormente, también en esos casos la concepción que el Legislador tenga sobre lo que es la persona humana o los ámbitos de la naturaleza y la cultura, tiene una función preponderante.

\section{2.) QUE LA LEY SE APLIQUE IGUAL A LOS IGUALES (ARTÍCULO $19 \mathrm{~N}^{\circ} 3$ )}

El principio constitucional de no discriminación, a la luz del artículo $19 \mathrm{~N}^{\circ} 3$ de la Constitución, significa, grosso modo, que el juez debe aplicar la ley igual a los iguales y desigual a los desiguales. Infringe este principio el juez cuando no le aplica la ley a quien debía aplicársela, y cuando le aplica la ley a quien no debía aplicársela. La cuestión que aquí interesa es conocer cómo los jueces satisfacen la exigencia del principio constitucional de igualdad en relación a los sexos.

¿De qué modo responden los jueces ante las eventuales discriminaciones basadas en el sexo? Lo normal es que los jueces apliquen la ley sin cuestionarla. Esto no sorprende en Chile, que se caracteriza por la formación legalista (positivista) de sus jueces. ${ }^{35} \mathrm{El}$ juez en Chile se mueve dentro de los márgenes de la ley, más o menos estrechos, pero siempre acotado. Luego, su potencial capacidad para corregir las eventuales discriminaciones basadas en el sexo, está predeterminada por la ley. Pero no debe interpretarse esto como una especie de automatización en la aplicación de la ley. Es imposible una aplicación mecánica de las normas: siempre hay un grado de intervención subjetiva del juez, que puede comprenderse dentro del fenómeno de la creación judicial del Derecho ${ }^{36}$. En

35 Barros, Enrique y Squella, Agustín (1992): Seminario sobre la "Cultura Juridica Chilena. Santiago, Corporación de Promoción Universitaria, 159 pp.

36 Prieto SAnchís, Luis (2005): Interpretación juridica y creación judicial del derecho. Lima: Editorial Palestra, 295 pp. 
este sentido, cabe concebir un espacio en el que los jueces puedan corregir las discriminaciones arbitrarias entre el hombre y la mujer ${ }^{37}$.

La inevitable labor creativa del juez al aplicar la ley admite un más y un menos; hay interpretaciones más o menos apegadas al tenor literal del texto o al espíritu de la norma o a los diferentes factores que orientan la interpretación. Pero, en general, puede decirse que en cualquiera de estos casos en Chile se aplica la ley con un estricto apego a la letra ${ }^{38}$.

A continuación analizamos alguna jurisprudencia relacionada con el principio constitucional de no discriminación por sexo. El análisis comprende dos partes. En la primera se abordan algunos casos de aplicación de normas caracterizadas como discriminatorias contra la mujer por su sexo (casos normales) y los motivos de la decisión (criterios generales de aplicación). En la segunda parte se examina dos casos de aplicación de normas en hipótesis atípicas (casos excepcionales) y los motivos de la decisión (criterios especiales de aplicación).

\subsection{1.) Casos normales y criterios de aplicación general}

El grupo de los "casos normales" se configuró en base a una selección de las normas legales típicamente caracterizadas como discriminatorias de la mujer. Estas normas son el artículo 225 del Código Civil (tuición supletoria de los hijos); el artículo 203 del Código del Trabajo (obligación de salas cuna); el artículo 1749 del Código Civil (administración de la sociedad conyugal); el artículo 38 ter de la ley de Isapres (sexo como factor de la tabla de precios de los planes de salud). El análisis de estos casos tuvo como propósito conocer los criterios jurisprudenciales acerca del principio de no discriminación de la mujer.

Artículo 225 del Código Civil a la luz de la jurisprudencia

La norma que es objeto de este apartado, y que trata sobre la tuición personal de los hijos, ha sido motivo de bastante controversia en la doctrina ${ }^{39}$. Principalmente, se ha discutido el carácter discriminatorio de la

37 Todavía es interesante el estudio que analiza el recurso de protección desde la perspectiva de discriminación por sexo, aunque hayan pasado varios ańos desde que se hizo, porque muestra la escasa eficacia que este mecanismo ha tenido como cauce para proteger contra la discriminación: Gómez, Gastón y FigueroA, Rodolfo (2000): "Discriminación en contra de la mujer y Recurso de Protección”, Informe de Investigación, N 8, Año 2, Universidad Diego Portales, Facultad de Derecho.

38 Muy distinto es, en cambio, el grupo de casos en que los jueces enjuician la ley y deciden si aplicarla o no. Este segundo grupo corresponde normalmente a la justicia constitucional (Tribunal Constitucional) o internacional (Corte Interamericana de Derechos Humanos).

39 Turner, Susan (2004), "Sentencia sobre Determinación de la Titularidad del Cuidado Personal de los Hijos Menores (Corte de Apelaciones de Santiago)", Revista de Derecho, Vol. XVII,, p 273-278; Rodríguez, María Sara (2009): "El cuidado personal de niños y adolescentes en la familia separada: criterios de resolución de conflictos de intereses entre padres e 
norma contra la mujer, en cuanto presume un supuesto "orden natural" que justificaría la preferencia legal de la madre como titular de la tuición de los hijos. Esta presunción sería perjudicial para la madre porque, por ejemplo, le impediría progresar en el ámbito laboral.

En el artículo 225 del Código Civil se determina quién ejerce el cuidado personal de sus hijos, en los casos de un quiebre de la relación entre el padre y la madre. Se pueden distinguir en la norma tres tipos de adjudicación: legal, judicial, y convencional. La adjudicación legal está contemplada en el inciso primero del artículo 225, otorgando la ley la tuición supletoria a la madre en caso de que ambos vivan separados. La adjudicación convencional y judicial se encontraría regulada en el inciso segundo y tercero respectivamente.

El estudio de los fallos que tienen relación con la aplicación de la norma en estudio, descubre un punto que es preciso destacar desde el principio: el juez tiene inclinación por aplicar la regla del "orden natural" que está expresada en el inciso primero del artículo 225 del Código Civil. Así, en varios fallos se resuelve otorgar la tuición a la madre, argumentando los jueces que ese criterio es favor filii, “ya que por lógica y por obra de la naturaleza, los hijos deben estar al lado de la madre" 40 .

Un elemento que ha modificado las coordenadas del debate en torno a la regla de atribución del artículo 225 inciso 1 del Código Civil es el interés superior del niño. El factor decisivo en la decisión de la tuición parece haberse ido trasladando desde la criterio del "orden natural" al criterio del "interés superior del niño", como lo dice la Corte de Apelaciones

hijos en el nuevo Derecho chileno de Familia”, en: Rev. chil. derecho [online]. 2009, Vol.36, n.3, pp. 545-586. ISSN 0718-3437. doi: 10.4067/S0718-34372009000300005; BAEZA, Gloria y Navarro, Marco Antonio (2004): "Derecho de los menores a vivir en una familia normalmente constituida”, Revista Chilena de Derecho, Vol. 31 n $^{\circ} 3$, pp. 575-592; Lathrop, Fabiola (2010a): "(In)constitucionalidad de la regla de atribución preferente materna del cuidado personal de los hijos del artículo 225 del Código Civil chileno”, Ius et Praxis [online], Vol.16, n.2 [citado 2011-11-03], pp. 147-184. Disponible en: <http://www.scielo.cl/ scielo.php?script=sci_arttext\&pid=S0718-00122010000200006\&lng=es\&nrm=iso $>$. ISSN 0718-0012. doi: 10.4067/S0718-00122010000200006; ETCHEBERRY, Leonor (2011): "Derecho de familia, sucesorio y regímenes matrimoniales", Revista Chilena de Derecho Privado, No 17, pp. 261-264; Lathrop, Fabiola (2010b): "Custodia compartida, acuerdo de los padres y establecimiento de oficio: un fallo en ausencia de ley (Corte de Apelaciones de Santiago)", Revista de Derecho, Vol. XXIII - No 2, pp. 237-245. hing No 30008. Confirman esta tesis numerosos fallos que se inclinan por aplicar la regla del "orden natural" contemplada en el inciso primero del Artículo 225 del Código Civil: CORTE De Apelaciones de SAntiago. 9 de junio de 2011. Rol No 2046-2010. "Pereira con Pereira”. LegalPublishing No 49956; corte suprema. 2 de febrero de 2011. Rol No 84542010. "Castillo con Santander". LegalPublishing No 48010; CORTE DE APELACIONES DE RANCAGUA. 30 de diciembre de 2010. Rol No 328-2010. "Munita con Silva". LegalPublishing No 47113; Corte suprema. 9 de agosto de 2010. Rol No 3834-2010. "Lucero con Jara". Legal Publishing No 45141; corte de apelaciones de san miguel. 4 de mayo de 2010. Rol No 148-2010. "Quezada con Quintanilla”. LegalPublishing No 45560, entre otros. 
de Chillán: "si bien el cuidado de los niños, desde tiempos inmemoriales, ha tocado a la madre por razones naturales, ese cuidado ha evolucionado en aras del interés superior del niño y en desmedro de los deseos de los progenitores, sin atender a sus dificultades o desavenencias" 41 . El interés superior del niño se presenta como un nuevo criterio de atribución de la tuición, pero no está clara la relación que guarda con la regla del inciso $1^{\circ}$ del artículo 225 del Código Civil: ¿son alternativos?, ¿se complementan?, ¿son lo mismo dicho con palabras distintas?, ¿uno remplaza al otro? "La ley no es clara en cuanto a si se ha mantenido la preferencia materna como regla de atribución judicial, ya que el artículo 225 inciso 3 Código Civil no señala con exactitud si el criterio que debe aplicar el juez es el interés superior del hijo o la preferencia materna del inciso primero del mismo articulo" 42.

La Corte Suprema se ha pronunciado sobre la relación que vincularía ambos conceptos: "... el principio del interés superior del niño constituye un principio fundamental en nuestro ordenamiento juridico, que junto con el derecho a ser oído el menor, constituyen los fundamentos sobre la base de los cuales los jueces del fondo han de fundar su decisión. (...) La regla de orden natural prevista en el articulo 225 del Código Civil, en orden a que la crianza de los hijos, en caso de separación de los padres, corresponde a la madre, y no se puede modificar si se solicita un régimen distinto, a menos que existan motivos que lo justifiquen, como sería si esta estuviese afectada por inhabilidad o el interés de la propia menor asi lo aconsejare" 43.

A primera vista, la cuestión acerca del criterio de atribución parece importante desde la perspectiva de la discriminación por sexo, porque la regla del inciso $1^{\circ}$ artículo 225 del Código Civil discriminaría entre el hombre y la mujer, mientras que el interés superior del niño no. Esto significaría que la aplicación del criterio del interés superior del niño superaría el problema de discriminación entre hombre y mujer que implica la aplicación del criterio del orden natural. En otras palabras, los jueces tendrían la posibilidad de eludir el problema de la discriminación por sexo sirviéndose del interés superior del niño como criterio para decidir, desplazando la regla del orden natural a una posición supletoria ${ }^{44}$.

41 Corte de Apelaciones de Chillán. 24 de abril de 2008. Rol No 90-2008. “San Martín con Stafan”. LegalPublishing No 38835.

42 Lathrop (2010a), p. 158.

43 Corte Suprema. 15 de julio de 2008. Rol No 3097-2008. "San Martín con Staffan". Legal Publishing No 39470.

44 Así podría inferirse de las palabras de la profesora Rodríguez: "El espíritu de la ley de Filiación $N^{o} 19.585$ habría sido dejar subsistente la preferencia materna solo como regla legal supletoria y no como criterio judicial. El criterio judicial sería el interés superior de los hijos", RoDRÍGUez (2009), p. 64. Pero esta interpretación es discutida, porque en realidad la regla de atribución legal prácticamente coincidiría con la regla de atribución judicial: “...creemos que el juez sí aplica esta preferencia materna, porque entiende que entre ella y dicho interés superior [del niño] hay sinonimia. Esta cuestión explicaría que, muy escasamente, se otorgue judicialmente al padre el cuidado personal", LATHRop (2010a), pp. 154-155. Esta segunda posición esta- 
- Artículo 203 del Código del Trabajo: análisis y alcance

El artículo 203 del Código del Trabajo se refiere a la obligatoriedad de salas cuna en los casos de empresas que ocupan veinte o más trabajadoras. Esta norma ha sido señalada como una de las barreras importantes en lo que respecta al empleo formal femenino en nuestro país ${ }^{45}$. En efecto, existe amplio consenso en los distintos sectores, en relación a que este artículo es una norma discriminatoria contra la mujer y una barrera de entrada a las posibilidades laborales que ofrece el mercado ${ }^{46}$.

¿Cómo ha sido interpretada esta norma por aquellos que deben hacerla cumplir? Los llamados a interpretarla, ¿cómo han reaccionado frente al efecto eventualmente discriminador que esta norma tiene respecto de la mujer? Para responder a estas interrogantes, conviene fijarse en la jurisprudencia de la Dirección del Trabajo, por ser más abundante que la judicial. A partir de los dictámenes de la Dirección del Trabajo, se puede decir que la interpretación de la norma no ha considerado el eventual efecto discriminatorio que su aplicación conlleva. Velando porque el cumplimiento del artículo 203 del Código del Trabajo se ajuste a sus términos literales, podría decirse que la Dirección del Trabajo ha puesto al descubierto el efecto discriminatorio de la norma. El énfasis de este órgano administrativo en

rá respaldada, por ejemplo, por la Corte de Apelaciones de San Miguel, cuando dijo que, al entregar "la tuición de hijos menores a la madre en caso que los padres vivan separados, muestra que se hizo primar el principio del interés superior del niño por sobre el principio de igualdad, estimando que ello constituye un hecho natural, por ser la madre más idónea, regla que solo puede alterarse cuando el interés del niño lo haga indispensable, sea por maltrato, descuido u otra causa justificada, en cuyo caso faculta al juez para entregar su cuidado personal al otro de los progenitores”, C. de Apelaciones San Miguel. Rol No 148-2010. LegalPublishing No 45560.

45 RAU, Tomás (2010): “El trabajo a tiempo parcial en Chile”, Economía chilena, Vol. 13, № 1 , pp. 39-59.

46 Libertad y Desarrollo (2010): “Mujer y Trabajo: Una Mirada Modernizadora”, en Temas Públicos, No 977 [Fecha de consulta: 19 de octubre de 2011]. Disponible en: http://200.111.119.228/wp-content/uploads/2011/05/TP977MujeryTrabajo.pdf.; ENCLA 2008 (2009): Inequidades y brechas de género en el empleo.Santiago: Dirección del Trabajo, p. 119. La razón por la cual se considera que es una discriminación arbitraria contra la mujer, corresponde a que el artículo 203 es una carga que soporta únicamente el empleador de la madre, provocando así una desigualdad entre el hombre y mujer para acceder -en igualdad de condiciones- a un empleo. Existen indicios de una modificación legal del artículo, en aras de un financiamiento compartido: Temas Públicos $\mathrm{N}^{\circ} 1.061,11$ de mayo de 2012, disponible en http://www.lyd.com/wp-content/files_mf/tp1061 provisiondesalacunauncambioimpostergable11052012.pdf. Un antecedente de propuesta, con información útil, en Temas Públicos $\mathrm{N}^{\circ} 1.052,9$ de marzo de 2012, disponible en http://www.lyd.com/wp-content/ files_mf/tp1052salacuna16.pdf. Sobre el financiamiento compartido: Uribe-Echeverría, Verónica (2008): Inequidades de género en el mercado laboral: el rol de la división sexual del trabajo, en Cuadernos de Investigación, $\mathrm{N}^{\circ} 35$, Dirección del Trabajo, noviembre de 2008, disponible en http:/www.estudiosdeltrabajo.cl/wp-content/uploads/2009/12/inequidades-de-genero-en-mercado-laboral-v-uribe-echevarria.pdf. Una crítica a la actual configuración del derecho a sala cuna, en CAAmaño, Eduardo (2011): Mujer, trabajo y derecho: Hacia relaciones laborales con equidad de género y corresponsabilidad social. Santiago: Editorial Abeleldo Perrot, pp. 73-77. 
los deberes que afectan al empleador ha dejado en evidencia el efecto negativo que tiene esta disposición en la empleabilidad de la mujer ${ }^{47}$.

Debido a que existe un consenso relativamente amplio en que la citada norma es una barrera al empleo formal femenino en nuestro país, afectando especialmente a las mujeres con baja calificación o más vulnerables, se ha instalado la necesidad de derogar esta norma o, en su defecto, modificarla creando un financiamiento compartido en materia de salas cuna entre empleadores del padre y la madre. Así, el Proyecto de Ley (Boletín No 7555-13), propone "modificar el actual artículo 203 del Código del Trabajo, estableciendo la obligación de sala cuna a las empresas que tengan 20 o más trabajadores, sean hombres o mujeres, extendiendo este derecho a los trabajadores hombres, y poniendo fin a la discriminación en la contratación de mujeres por este motivo" 48 .

- $\quad$ Síntesis de la jurisprudencia sobre el artículo 1749 Código Civil

La sociedad conyugal, establecida por el artículo 1749 del Código Civil, es objeto de polémica en la doctrina nacional, por el supuesto carácter discriminatorio en contra de la mujer ${ }^{49}$. Pese a los reparos que la

47 CaAmaño, Eduardo (2004): “Conciliación de trabajo y vida familiar. Un análisis desde la perspectiva del derecho del trabajo chileno”, Revista de Derecho, Vol. XVI, p. 59-82. Revisar dictámenes No 5952/374, de 9 de diciembre de 1999, y No 2233/129, de 15 de julio de 2002, Dictamen No 0059/002, 7 de enero de 2010, entre otros. No deja de ser paradójica la situación en contraste con las expectativas que suscitó la ley durante su tramitación: "El proyecto constituye un avance cierto en la protección de los derechos de la maternidad y, al mismo tiempo, versa sobre la igualdad de oportunidades que debe existir entre trabajadores y trabajadoras, a la que, como pais, nos hemos obligado por la Convención sobre la eliminación de todas las formas de discriminación con la mujer, Cedaw, y el Convenio $N^{\circ} 156$ sobre trabajadores y trabajadoras con responsabilidades familiares, de la Organización Internacional del Trabajo" (Laura Albornoz, entonces Ministra del SERNAM, tercer trámite constitucional, Cámara de Diputados, Legislatura 354, sesión 123 (Boletín 7555-13).

48 Mensaje del Proyecto de ley que "Modifica el artículo 203 del Código del Trabajo, ampliando el derecho a Sala Cuna para hombres y mujeres trabajadoras", Boletín 7555-13. Algunos datos estadísticos sobre la materia en http://www.dt.gob.cl/documentacion/1612/w3-article-95958.html

49 Gatica, María Paz (2011). "El destino de la sociedad conyugal” [fecha de consulta: 17 de octubre de 2011]. Disponible en http://www.cdh.uchile.cl/media/publicaciones/anuarios/ anuario07/12-GATICA.pdf..; Domínguez, Carmen (1999): "La situación de la mujer casada en el régimen patrimonial chileno: mito o realidad, Revista Chilena de Derecho, Vol. 26, N 1, pp. 87-103; Bustamante, Luis (1997): "Plena capacidad de la mujer casada en sociedad conyugal en Chile. Una reforma legal por hacer: sentido y alcance de la ley 18.802", en Anuario de la Universidad Internacional SEK, No. 3, pp. 149-160; UlloA, Jorge (2010): "La sociedad conyugal. Una perspectiva dinámica”, en Ars Boni et Aequi, Vol. 6, No 1, pp. 255268; Lathrop, Fabiola (2008): "Discriminación contra la mujer en los regímenes de bienes del matrimonio. El caso chileno", en Ángela Figueruelo (edit), Estudios interdisciplinarios sobre igualdad y violencia de género. Granada: Editorial Comares, pp. 221-248; Rodríguez, Pablo (2000): "Innovaciones en materia de Regímenes Patrimoniales", Revista Actualidad Jurídica, $\mathrm{N}^{\circ}$ 1, pp. 193-232; BARAONA, Jorge (2007): "La sociedad conyugal puede ser corregida sin suprimirse”, La Semana Jurídica, pp. 3; TAPIA, Mauricio (2007): "Sociedad conyugal y comunidad de gananciales. Críticas a su proyecto de reforma”, La Semana Jurídica, año 7 , 
doctrina ha hecho de ella, no hemos sabido de ninguna sentencia en que los tribunales ordinarios hayan cuestionado su contenido desde la perspectiva de la discriminación por razones de sexo.

El análisis de las sentencias de la justicia ordinaria permite afirmar que los cuestionamientos que se le han hecho a la sociedad conyugal, por su eventual contenido discriminatorio, no han permeado en la jurisprudencia. Obviamente, existen muchas resoluciones acerca del sentido y alcance del artículo 1749 del Código Civil, pero ninguna discutiéndolo desde la perspectiva del principio constitucional de igualdad hombremujer. Los pronunciamientos judiciales se refieren, por ejemplo, a la naturaleza de la institución ${ }^{50}$, o al carácter de la autorización que debe dar el marido ${ }^{51}$, o a la supletoriedad de la autorización judicial ${ }^{52}$, o la sanción que se sigue de la falta de autorización ${ }^{53}$.

Los fallos analizados vienen simplemente a confirmar lo dispuesto por el artículo 1749 del Código Civil, en cuanto a que le corresponde al marido -como jefe de la sociedad conyugal- la administración de los bienes sociales y los de su mujer, sin perjuicio de las limitaciones que se indican en los mismos preceptos. Los tribunales ordinarios de justicia, al pronunciarse en los casos relativos al artículo 1749 del Código Civil, no hacen más que aplicar el contenido de la norma y confirmar sus efectos, sin cuestionarse el supuesto establecido por el Legislador en lo que respecta a las reglas de administración de sociedad conyugal. Así, podría decirse que la jurisprudencia judicial legitima su contenido al no cuestionarlo.

- El artículo 38 ter de la ley de Isapres en la jurisprudencia de protección

El artículo 38 ter de la Ley de Isapres contemplaba el sexo como uno de los factores para calcular las alzas a los precios de los planes de salud. En el caso de las mujeres, las alzas eran mayores que en el de los hombres. Esta norma legal ha sido objeto de numerosísimos fallos en juicios de protección. Uno de los argumentos que se alega en las Cortes es el carácter discriminatorio que entraña la consideración del sexo como criterio para distinguir las alzas de precios de los planes de salud.

Los tribunales ordinarios han fallado reiteradamente que el actuar de las Isapres en las variaciones de los precios en los contratos de salud, en

N³60, pp. 6-7; BEAudry, Jonas-Sebastien (2010): "La desigualdad de género en el régimen matrimonial chileno", University of Miami Inter-American Law Review, Vol. 41, pp. 187-219. Corte de Apelaciones de Santiago. 16 de octubre de 2008. Rol No 10145-2005. "Vélez con Calquin", LegalPublishing No 40461.

51 Corte de Apelaciones de Santiago. 30 de enero de 2008. Rol No 9082-2002. "Hughes con Banco Internacional". LegalPublishing No 38310.

52 Corte de Apelaciones de Valparaíso. 7 de mayo de 1991. Rol No 113021. "Orellana con Vicencio". LegalPublishing No 11228.

53 Corte Suprema. 30 de octubre de 2010. Rol No 3715-2000. "Rehl con Gómez". LegalPublishing No 17440 . 
aplicación de la tabla de factores por edad y sexo, constituye "una discriminación carente de fundamento que impide a una persona (...) mantenerse en el plan contratado" 54 . Por consiguiente, la jurisprudencia ha sido uniforme y reiterativa en sostener que la variación de precio de los contratos de salud vulnera los derechos y garantías constitucionales, especialmente los $\mathrm{N}^{\circ}$ s 1, 2 y 24 del Artículo 19 de la Constitución.

No obstante la abundancia de fallos en la materia, no existe un desarrollo en torno al eventual efecto discriminatorio del sexo como factor de ajuste del precio del plan de salud. Aunque los tribunales han sido majaderos en considerar contrario a la igualdad el alza de precio basado en el sexo del cotizante, no han desarrollado una fundamentación del criterio. Lo normal es una declaración que sencillamente constata la discriminación que significa considerar el sexo como uno de los factores determinantes en el precio del plan de salud. Probablemente, esto se deba a que el efecto eventualmente discriminatorio del sexo no se ha discutido por los recurrentes desde la perspectiva de la injusticia que supondría para las mujeres respecto de los hombres. Sencillamente se ha objetado el hecho de que el sexo sea uno de los factores a considerar en el alza de precios, con independencia de si es femenino o masculino.

\subsection{2.) Casos excepcionales y criterios de aplicación especial}

En este último apartado se comprende el análisis de dos casos que pueden calificarse de excepcionales, desde la perspectiva de la discriminación sexual en Chile. Lo que permite calificar como excepcional a estos casos, es la consideración de la igualdad entre hombre y mujer como el argumento central de la decisión. En el contexto de los supuestos analizados en el apartado anterior, el razonamiento de las sentencias en estos dos casos resalta por contraste. El primer caso es un juicio por violación seguido por la mujer en contra de su marido. El segundo caso es un juicio por la aplicación de una condición para contraer segundas nupcias.

- Violación a la cónyuge 55

En Villarrica se siguió juicio contra un hombre por violación de su cónyuge. Los hechos no fueron controvertidos, porque el acusado siempre

54 Por todos, Corte Suprema. 17 de noviembre de 2004. Rol No 5036-2004. "Gómez y Aninat con Isapre ING Salud S.A”. LegalPublishing No 31399.

55 Tribunal Oral en lo Penal, Villarrica. 25 de mayo de 2007. Rol No 27-2007. "Contra René Coñoeman”. LegalPublishing No 41050. Un análisis amplio de leyes penales desde una perspectiva de género, Garafulic, María Paz (2001): Mujer y derecho: una aproximación a la situación legal de la mujer en tres paises latinoamericanos, Argentina, Chile, Perú. Santiago, Proyecto Fundación Ford, pp. 214-250. Se refiere indirectamente al supuesto de violación entre cónyuges en p. 243. El Código Penal chileno reconoce expresamente la violación del cónyuge o conviviente en el artículo 369 inc. $4^{\circ}$. 
reconoció haber sostenido la relación que su mujer denunció como violación. El debate se centró en la valoración de este hecho. Para el marido, la relación sexual con su mujer es siempre lícita, porque se enmarca en el contrato de matrimonio, que comprende los deberes de cohabitar y procrear. Luego, aunque el marido no está expresamente excluido de la conducta descrita en el artículo $361 \mathrm{~N}^{\circ} 1$ del Código Penal, se entiende que entre los cónyuges no puede haber violación.

El Tribunal Penal Oral ponderó las razones para sostener que en el matrimonio no existe violación, y las desechó. El Tribunal hizo suyas las opiniones de un autor espańol, porque esas opiniones corresponderían a "una concepción moderna en la cual el rol del hombre con la mujer está dada en una relación de igualdad" (considerando séptimo). El Tribunal, citando al autor español, sostuvo que el error de quienes niegan la posibilidad de violación en el matrimonio se basa "en la creencia falsa de que la mujer, al contraer matrimonio, hipoteca al marido su libertad sexual y se convierte en su sierva, confundiendo lamentablemente el deber juridico de fidelidad de la esposa y la libertad sexual de la misma" (considerando séptimo).

La justicia en este caso exige respetar la igualdad entre hombre y mujer: aceptar que la mujer no puede ser violada por su cónyuge "subvertiría el orden ético jurídico de la organización familiar moderna y se convertiría a la mujer en un instrumento de placer" (considerando séptimo). En apoyo de esta concepción el Tribunal invocó el tratado internacional firmado en Viena en 1993 y las convenciones de Copenhague y Beijing, además de otras legislaciones comparadas (considerandos séptimo y octavo).

Lo interesante de este caso es que la interpretación del artículo 361 $N^{\circ} 1$ del Código Penal estuvo determinada por el principio de igualdad entre el hombre y la mujer. Aunque no conocemos ningún caso en que se haya desechado una acusación de violación con el argumento de que en el matrimonio esta conducta no es posible, se puede advertir en la sentencia que comentamos la intención abierta de superar una determinada concepción de la situación de la mujer casada respecto de su marido ${ }^{56}$.

- La condición para casarse por segunda vez ${ }^{57}$

La Segunda Sala de la Corte de Apelaciones de Santiago acogió un recurso de apelación y revocó la sentencia de primera instancia que rechazó la solicitud de autorización de una mujer para casarse por segunda vez, después de haberse divorciado. El Tercer Juzgado de Familia de Santiago rechazó la solicitud presentada por la mujer, porque al momento de hacerlo se encontraba embarazada. Y el artículo 128 del Código Civil dispo-

56 La Ley $\mathrm{N}^{\circ} 20.480$ incorporó al Código Penal una modificación al procedimiento por violación a cónyuge o conviviente (artículo 369 inc. 4º). SANTibáñEZ y VARgas (2011), pp. 203-204.

57 Corte de Apelaciones de Santiago. 9 de abril de 2009. Rol No 136-2009. "Carrasco con Duarte”. LegalPublishing No 42300. 
ne que cuando un matrimonio se ha disuelto la mujer no puede contraer segundas nupcias si está embarazada.

El matrimonio de la mujer se declaró disuelto por sentencia judicial el 8 de octubre de 2008. Transcurridos los 270 días que exige la segunda parte del inciso $1^{\circ}$ del artículo 128 del Código Civil, solicitó la autorización para contraer segundas nupcias. Esta autorización, como queda dicho, le fue rechazada porque estaba embarazada. Apeló contra esta sentencia, invocando la regla del inciso $2^{\circ}$ del mismo artículo, que permite rebajar del plazo de los 270 días todos aquellos días inmediatamente anteriores a la disolución del matrimonio, en que haya sido "absolutamente imposible el acceso del hombre a la mujer".

Dijo la Corte en el considerando cuarto de la sentencia: "Es cierto que la terminología que usa el Código Civil -'absolutamente imposible el acceso'- podría entenderse referida nada más a un impedimento de carácter físico o material como si, por ejemplo, uno de los cónyuges hubiere estado en un sitio muy lejano del otro o que uno cualquiera de ellos hubiere caido en minusvalia impediente de vinculo intimo. Empero, creen estos jueces que hoy por hoy no corresponde restringir el entendimiento del precepto a ese solo punto de vista, como quiera que está concebido y redactado a mediados del siglo $X I X$, cuando no habian advenido aún los tiempos de una cultura como la que impera en los comienzos del siglo XXI en la que los intereses de la mujer y su libertad reproductiva no quedan juridicamente supeditados al matrimonio $y$, menos, al cónyuge. Aparte de lo cual no puede sino asumirse que el sentido de la disposición no puede ser el mismo ayer que hoy, habida cuenta los adelantos cientificos que permiten en el presente conocer el estado de embarazo de manera lo suficientemente temprana como para atender a los plazos del código centenario. Por lo que es también dable inteligir la imposibilidad del inciso segundo del artículo 128 como una de carácter ético y/o costumbrista".

El punto más interesante del razonamiento de la Corte, en el contexto de este trabajo, es la constatación del cambio cultural que inspira la comprensión de la disposición legal. Para la Corte resulta comprensible que el siglo XIX se consagrara una restricción de la libertad de la mujer como la del artículo 128 del Código Civil. Pero en el siglo XXI, tiempo en el que impera una cultura "en la que los intereses de la mujer y su libertad reproductiva no quedan juridicamente supeditados al matrimonio $y$, menos, al cónyuge”, tal restricción no sería aceptable. En razón de este nuevo paradigma, cabría interpretar "la imposibilidad del inciso segundo del artículo 128 como una de carácter ético y/o costumbrista”.

\section{CONCLUSIONES}

La diferencia de los sexos plantea un constante desafío para el Legislador y para el Juez, desde la perspectiva del principio constitucional de la 
igualdad. La premisa de que no se puede discriminar arbitrariamente en razón del sexo es acogida de diferentes maneras por el Juez y el Legislador, de acuerdo con la naturaleza y posibilidades de sus específicas funciones. En base a los casos analizados en este trabajo, se corrobora lo que era hipotéticamente predecible: el Legislador goza de un rango cualitativamente más amplio que el Juez para ofrecer una respuesta a las desigualdades basadas en el sexo. El Juez, a diferencia del Legislador, normalmente se mueve en el margen relativamente estrecho que le demarca la ley. Esta diferencia explica que la preponderancia de los factores extrajurídicos (v.gr. concepción antropológica; delimitación de los ámbitos cultura/naturaleza) sea mucho mayor en la actividad legislativa que en la actividad judicial.

\section{BIBLIOGRAFÍA}

- Arregui, Jorge y Rodríguez, Carlos (1995): Inventar la sexualidad: sexo, naturaleza y cultura. Madrid: Ediciones Rialp, S.A., pp 87-98.

- Azkárate, Ana Carmen (1997): Mujer y discriminación: del tribunal de justicia de las comunidades al tribunal constitucional. Bilbao: Instituto Vasco de Administración Pública, pp. 89-130.

- Baeza, Gloria y Navarro, Marco Antonio (2004): "Derecho de los menores a vivir en una familia normalmente constituida", Revista Chilena de Derecho, Vol. 31 n $^{\circ}$ 3, pp. 575-592.

- Baraona, Jorge (2007): "La sociedad conyugal puede ser corregida sin suprimirse", La Semana Jurídica, p. 3.

- Barros, Enrique y Squella, Agustín (1992): Seminario sobre la "Cultura Jurídica Chilena. Santiago, Corporación de Promoción Universitaria, 159 pp.

- Barrère, María Ángeles (1997): Discriminación, derecho antidiscriminatorio y acción positiva en favor de las mujeres. Madrid: Civitas, 123 pp.

- Beaudry, Jonas-Sebastien (2010): "La desigualdad de género en el régimen matrimonial chileno", University of Miami Inter-American Law Review, Vol. 41, pp. 187-219.

- Воввіо, Norberto (1993): Igualdad y libertad. Barcelona: Editorial Paidós, $154 \mathrm{pp}$.

- Bustamante, Luis (1997): "Plena capacidad de la mujer casada en sociedad conyugal en Chile. Una reforma legal por hacer: sentido y alcance de la Ley 18.802", en Anuario de la Universidad Internacional SEK, No. 3, pp. 149-160.

- CaAmaño, Eduardo (2004): "Conciliación de trabajo y vida familiar. Un análisis desde la perspectiva del derecho del trabajo chileno", Revista de Derecho, Vol. XVI, p. 59-82. 
- CaAmaño, Eduardo (2005): El derecho a la no discriminación en el empleo. Santiago de Chile: LexisNexis, 327pp.

- CaAmaño, Eduardo (2011): Mujer, trabajo y derecho: Hacia relaciones laborales con equidad de género y corresponsabilidad social. Santiago: Editorial Abeledo Perrot, p. 73-77.

- Cardozo, Benjamín N. (1922): The Nature of the Judicial Process. Oxford University Press, 180 pp.

- Corral, Hernán (2007): Derecho civil y persona humana. Cuestiones debatidas. Santiago: Lexis Nexis, 254 pp.

- Domínguez, Carmen (1999): "La situación de la mujer casada en el régimen patrimonial chileno: mito o realidad, Revista Chilena de Derecho, Vol. 26, N 1 , pp. 87-103.

- Etcheberry, Leonor (2011): "Derecho de familia, sucesorio y regímenes matrimoniales", Revista Chilena de Derecho Privado, No 17, pp. 261-264.

- Elósegui, María (2003): Las acciones positivas para la igualdad de oportunidades laborales entre mujeres y hombres: un análisis de la legislación alemana y la Directiva 76/207/CEE desde la teoría de la argumentación de Robert Alexy. Madrid: Editorial Centro de Estudios Políticos y Constitucionales, pp. 53-117.

- Encla 2008 (2009): Inequidades y brechas de género en el empleo. Santiago: Dirección del Trabajo, 177 pp.

- Fernández, Miguel Ángel (2001): Principio constitucional de igualdad ante la ley. Santiago: Editorial ConoSur, pp. 117-118.

- Figueruelo, Ángela (2008): Estudios interdisciplinares sobre igualdad y violencia de género. Granada: Editorial Comares, 464 pp.

- Gamonal, Sergio (2001): "La lucha contra la discriminación femenina: las acciones positivas y su constitucionalidad", en Revista Laboral Chilena, $\mathrm{N}^{\circ}$ 98, pp. 69-79.

- Garafulic, María Paz (2001): Mujer y derecho: una aproximación a la situación legal de la mujer en tres paises latinoamericanos, Argentina, Chile, Perú. Santiago, Proyecto Fundación Ford, pp. 214-250.

- Gatica, María Paz (2011). "El destino de la sociedad conyugal" [fecha de consulta: 17 de octubre de 2011]. Disponible en http:// www.cdh.uchile.cl/media/publicaciones/anuarios/anuario07/12GATICA.pdf.

- Gímenez Gluck, David (1999): Una manifestación polémica del principio de igualdad: acciones positivas moderadas y medidas de discriminación inversa. Valencia: Editorial Lo Blanch, pp. 58-75.

- González del TÁnago, Lourdes et al. (1993); Igualdad de trato entre mujeres y hombres en la jurisprudencia europea. Madrid: Consejería de Presidencia, Dirección de la Mujer, Dirección General de Cooperación con el Estado y Asuntos Europeos, pp. 29-243. 
- Gómez, Gastón y Figueroa, Rodolfo (2000): "Discriminación en contra de la mujer y Recurso de Protección", Informe de Investigación, $\mathrm{N}^{\circ}$ 8, Año 2, Universidad Diego Portales, Facultad de Derecho.

- Henríquez, Helia y Riquelme, Verónica (2010): “El derecho a ganar lo mismo: ley 20.348 : igualdad de remuneraciones entre hombres y mujeres", Temas Laborales, $\mathrm{N}^{\circ} 27$, pp. 1-29.

- Lathrop, Fabiola (2010a): “(In)constitucionalidad de la regla de atribución preferente materna del cuidado personal de los hijos del artículo 225 del Código Civil chileno", Ius et Praxis [online], Vol.16, n.2 [citado 2011-11-03], pp. 147-184. Disponible en: $<$ http://www.scielo.cl/scielo.php?script=sci_arttext\&pid=S071800122010000200006\&lng=es\&nrm=iso >. ISSN 0718-0012. doi: 10.4067/S0718-00122010000200006.

- Lathrop, Fabiola (2010b): "Custodia compartida, acuerdo de los padres y establecimiento de oficio: un fallo en ausencia de ley (Corte de Apelaciones de Santiago)", Revista de Derecho, Vol. XXIII - No 2 pp. 237-245.

- Lathrop, Fabiola (2008): Discriminación contra la mujer en los regímenes de bienes del matrimonio. El caso chileno, en Ángela Figueruelo (edit), Estudios interdisciplinarios sobre igualdad y violencia de género. Granada: Editorial Comares, pp. 221-248.

- Libertad y Desarrollo (2010): "Mujer y Trabajo: Una Mirada Modernizadora", en Temas Públicos, No 977 [Fecha de consulta: 19 de octubre de 2011]. Disponible en: http://200.111.119.228/wpcontent/uploads/2011/05/TP977MujeryTrabajo.pdf.

- Navarro, Enrique (2012): "Igualdad ante la ley y jurisprudencia del Tribunal Constitucional" en Actualidad Jurídica, Vol. 13, N 26, pp. 63-96.

- Novales, Aránzazu (2004): Derecho antidiscriminatorio y género: las premisas invisibles, Santiago de Chile: Fondo de Desarrollo de las Naciones Unidas para la Mujer, pp. 47-172.

- Ollero, Andrés (1999): Discriminación por razón de sexo : valores, principios y normas en la jurisprudencia constitucional española. Prólogo de Miguel Rodríguez-Piñero Bravo-Ferrer. Madrid: Editorial Centro de Estudios Políticos y Constitucionales, 183 pp.

- PeñA, Jorge (2000): "Las diversas acepciones de naturaleza en su relación con la cultura", Anuario de Filosofía Jurídica y Social, $\mathrm{N}^{\circ} 18$, pp. 25-57.

- Pérez Luño, Antonio Enrique (2007): "Dimensiones de la igualdad", Cuadernos "Bartolomé de las Casas". 2a edición. Madrid: Editorial Dykinson. Volumen 34, 135 pp. 
- programa de las Naciones Unidas para el Desarrollo (2010): Desarrollo humano en Chile: género: los desafíos de la igualdad. Santiago: PNUD, p.368.

- PRieto SAnchís, Luis (2005): Interpretación juridica y creación judicial del derecho. Lima: Editorial Palestra, 295 pp.

- Rau, Tomás (2010): "El trabajo a tiempo parcial en Chile", Economia chilena, Vol. 13, $\mathrm{N}^{\circ} 1$, pp. 39-59.

- Ríos et al. (2008): El efecto de las leyes de cuota en la representación de las mujeres en América Latina”, en Ríos, Marcela (edit), Mujer y Politica. El impacto de las cuotas de género en América Latina (FLACSO-CHILE e IDEA Internacional). 250 pp.

- Rodríguez, Marcela (1999), en Género y Derecho, Alda Facio y Lorena Fries (edits.). Santiago, LOM, pp. 245-287.

- Rodríguez, María Sara (2009): "El cuidado personal de niños y adolescentes en la familia separada: criterios de resolución de conflictos de intereses entre padres e hijos en el nuevo Derecho chileno de Familia", en: Rev. chil. derecho [online]. 2009, Vol.36, n.3, pp. 545-586. ISSN 0718-3437. doi: 10.4067/S071834372009000300005.

- Rodríguez, Pablo (2000): "Innovaciones en materia de Regímenes Patrimoniales", Revista Actualidad Jurídica, No 1, pp. 193-232.

- Rosanvallon, Pierre (2012): La Sociedad de los Iguales. Barcelona: Editorial RBA LIBROS, 428 pp.

- Sandel, Michael (2010): Justicia: ¿Hacemos lo que debemos? Barcelona: Editorial Debate, 352 pp.

- Santibáñez, María Elena y Vargas, Tatiana (2011): "Reflexiones en torno a las modificaciones para sancionar el femicidio y otras reformas relacionadas (Ley $\mathrm{N}^{\circ}$ 20.480)", en Revista Chilena de Derecho, Vol. $38 \mathrm{~N}^{\circ}$ 1, pp. 193-207.

- Spaemann, Robert (1991): Felicidad y benevolencia. Madrid: RIALP, pp. 288.

- Tapia, Mauricio (2007): "Sociedad conyugal y comunidad de gananciales. Críticas a su proyecto de reforma”, La Semana Jurídica, año $7, N^{\circ} 360$, pp. 6-7.

- Turner, Susan (2004), "Sentencia Sobre Determinación de la Titularidad del Cuidado Personal de los Hijos Menores (Corte de Apelaciones de Santiago)", Revista de Derecho, Vol. XVII,, p 273-278.

- UlloA, Jorge (2010): "La sociedad conyugal. Una perspectiva dinámica”, en Ars Boni et Aequi, Vol. 6, No 1, pp. 255-268.

- Uribe-Echeverría, Verónica (2008): Inequidades de género en el mercado laboral: el rol de la división sexual del trabajo, en Cuadernos de Investigación, $\mathrm{N}^{\circ}$ 35, Dirección del Trabajo, noviembre de 2008, disponible en http://www.estudiosdeltrabajo.cl/wp-content/ 
uploads/2009/12/inequidades-de-genero-en-mercado-laboral-vuribe-echevarria.pdf.

- Zúñiga, Yanira (2003): "El derecho al desarrollo desde la perspectiva de género", Disponible en http://hdl.handle.net/10016/565.

\section{Normas citadas}

- Boletín 3206-18, Modifica diversos cuerpos legales con el objeto de promover el derecho de las mujeres a participar en la vida pública nacional, en http://www.camara.cl/pley/pley_detalle. aspx?prmID=3456.

- Boletín 7555-13, Modifica 203 del Código del Trabajo, ampliando el derecho a salas cuna, para hombre y mujeres trabajadoras, en http://www.camara.cl/pley/pley_detalle. aspx?prmID $=7950 \&$ prmBL $=7555-13$.

- Decreto No 789, Convención sobre eliminación de todas las formas de discriminación contra la mujer, también denominada "CEDAW". Diario Oficial, 9 de diciembre 1989.

- Decreto No 873, Convención Americana sobre Derechos Humanos, denominada "Pacto de San José de costa Rica". Diario Oficial, 5 de enero 1991.

- Decreto No 1640, Convención Interamericana para prevenir, sancionar y erradicar la violencia contra la mujer, también denominada "Convención de Belem do Pará". Diario Oficial, 11 de noviembre 1998.

- Historia de la Ley No 20.480, que modifica el Código Penal y la Ley $\mathrm{N}^{\circ} 20.066$ sobre Violencia intrafamiliar, estableciendo el "Femicidio", aumentando las penas aplicables a este delito y reforma las normas sobre Parricidio (2010).

\section{Jurisprudencia citada}

- Corte Suprema. 19 de abril de 2004. Rol No 67-2004. "Cazenave con Suazo". LegalPublishing No 30008.

- Corte Suprema. 17 de noviembre de 2004. Rol No 5036-2004. "Gómez y Aninat con Isapre ING Salud S.A". LegalPublishing No 31399.

- Corte Suprema. 15 de julio de 2008, Rol No 3097-2008. “San Martín con Staffan". LegalPublishing No 39470.

- Corte Suprema. 9 de agosto de 2010. Rol No 3834-2010. "Lucero con Jara". LegalPublishing No 45141.

- Corte Suprema. 30 de octubre de 2010. Rol No 3715-2000, "Rehl con Gómez". LegalPublishing No 17440. 
- Corte Suprema. 2 de febrero de 2011, Rol No 8454-2010. "Castillo con Santander". LegalPublishing No 48010.

- Corte de Apelaciones de Santiago. 30 de enero de 2008. Rol No 9082-2002. "Hughes con Banco Internacional. LegalPublishing No 38310.

- Corte de Apelaciones de Santiago. 16 de octubre de 2008. Rol No 10145-2005. "Vélez con Calquín”. LegalPublishing No 40461.

- Corte de Apelaciones de Santiago. 9 de abril de 2009. Rol No 136-2009. "Carrasco con Duarte". LegalPublishing No 42300.

- Corte de Apelaciones de Santiago. 9 de junio de 2011. Rol No 2046-2010, "Pereira con Pereira". LegalPublishing No 49956.

- Corte de Apelaciones de Rancagua, 30 de diciembre de 2010. Rol No 328-2010. "Munita con Silva", LegalPublishing No 47113.

- Corte de Apelaciones de Valparaíso. 7 de mayo de 1991. Rol No 113021. "Orellana con Vicencio". LegalPublishing No 11228.

- Corte de Apelaciones de San Miguel. 4 de mayo de 2010, Rol No 148-2010. "Quezada con Quintanilla". LegalPublishing No 45560.

- Corte de Apelaciones de Chillán. 24 de abril de 2008. Rol No 90-2008. "San Martín con Stafan". LegalPublishing No 38835.

- Tribunal Oral en lo Penal, Villarrica. 25 de mayo de 2007. Rol No 27-2007, “Contra René Coñoeman”. LegalPublishing No 41050.

- Dictamen Dirección del Trabajo No 0059/002, de 7 de enero de 2010.

- Dictamen Dirección del Trabajo No 2233/129, de 15 de julio de 2002.

- Dictamen Dirección del Trabajo No 5952/374, de 9 de diciembre de 1999. 